\title{
Processo formativo: reflexões de um professor que ensina matemática nos anos iniciais do Ensino Fundamental
}

\author{
Deusdete Luiz da Silva Filho \\ Pedro Henrique Milagre
}

\section{Resumo}

Este relato apresenta as reflexões de um dos autores, professor dos anos iniciais do Ensino Fundamental, após participar de um processo formativo desenvolvido no sul da Bahia em 2015, pelos projetos de pesquisa 'Um Estudo Sobre o Domínio das Estruturas Multiplicativas no Ensino Fundamental (E-Mult)' e as 'Estruturas Multiplicativas e a formação de professores que ensinam Matemática na Bahia (PEM)'. Além disso, discute sobre as experiências desse em outros processos formativos, assim como na formação inicial. Embasamo-nos em Tardif (2014), quando discute os saberes docentes e a formação profissional do professor e em Imbernón (2009), ao abordar a formação permanente do professorado. Iremos observar que o Professor se surpreendeu com o processo formativo desenvolvido pelo E-Mult, uma vez que esse aconteceu sem hierarquia entre os formadores e professores, o que não foi comum em outras formações que participou. Segundo ele, nesse processo formativo os professores tiveram voz, podendo opinar e discutir, o que foi uma oportunidade rica de aprender com o outro.

Palavras-chave: reflexões; processo formativo; anos iniciais do Ensino Fundamental. 


\section{Introdução}

O ser humano está em constante processo de aprendizagem. Aprendemos tarefas que consideremos úteis ao nosso cotidiano e ao convívio em sociedade. Diante disso, Tardif (2014, p. 57) apresenta que trabalhar também envolve um processo de aprendizagem, em que “[...] trabalhar remete a aprender a trabalhar, ou seja, a dominar progressivamente os saberes necessários à realização do trabalho”. Salientando ainda que, em certos ofícios, por exemplo, os ligados a agricultura, pesca etc., o trabalho é aprendido pelas crianças e jovens por meio do contato direto e cotidiano com as tarefas realizadas pelos adultos. Em outras ocupações, como no caso do magistério, a aprendizagem do trabalho passa por uma escolarização, cuja função é fornecer conhecimentos teóricos e técnicos que os preparem para a realização do trabalho. Formação essa, que é completada por uma formação prática.

Nessa perspectiva, apresentaremos as reflexões de um dos autores desse relato, professor dos anos iniciais do Ensino Fundamental, após participar de um processo formativo, desenvolvido no sul da Bahia, por dois projetos de pesquisa entrelaçados. Um deles financiado pela Comissão de Aperfeiçoamento de Pessoal de Nível Superior (CAPES), junto ao Observatório da Educação (OBEDUC), desenvolvido em rede em três estados do Nordeste (Bahia, Ceará e Pernambuco) e envolvendo doze escolas parceiras, intitulado 'Um Estudo Sobre o Domínio das Estruturas Multiplicativas no Ensino Fundamental (E-Mult)'. O outro, responsável pelo projeto na Bahia, financiado pela Fundação de Amparo à Pesquisa do Estado da Bahia (FAPESB), desenvolvido em três escolas parceiras e intitulado 'As Estruturas Multiplicativas e a formação de professores que ensinam Matemática na Bahia (PEM)'.

Nesses projetos de pesquisa foram desenvolvidos três estudos: o primeiro consistiu em uma análise da Prova Brasil, o segundo foi um diagnóstico com alunos das escolas parceiras, com base na análise do primeiro estudo e o terceiro estudo foi um processo formativo com professores, envolvendo o Campo Conceitual Multiplicativo, de Gérard Vergnaud.

Esses projetos estão preocupados com a formação prática do professor que ensina Matemática, uma vez que o objetivo desses é: "Investigar e intervir na prática de professores do Ensino Fundamental no que tange às Estruturas Multiplicativas, baseados no modelo de formação 'ação-reflexão-planejamento-ação', tendo em vista a formação de um grupo com características colaborativas" (OBEDUC, Projeto de pesquisa, 2012¹).

Para possibilitar a compreensão do leitor ao longo do texto, ao apresentarmos as reflexões do autor que participou do processo formativo, o chamaremos de Professor $^{2}$, tendo em vista que o outro autor é um mestrando que realiza a pesquisa nesse projeto. Desta forma,

\footnotetext{
${ }^{1}$ Financiado pela Coordenação de Aperfeiçoamento de Pessoal de Nível Superior (CAPES), com a identificação 15727, a ser realização no período 2013-2017.

2 Possui 51 anos de idade, formação inicial em pedagogia e leciona há 04 anos. ISSN 2526-2882 
foi das discussões entre os autores que surgiu esse relato.

É importante destacar que embasaremos as reflexões apresentadas nesse relato em Tardif (2014), quando discute os saberes docentes e a formação profissional do professor e em Imbernón (2009), ao abordar a formação permanente do professorado.

Para tanto, esse relato foi estruturado nos seguintes tópicos: (1) Reflexões sobre a formação do professor dos anos iniciais do Ensino Fundamental; (2) O processo formativo desenvolvido pelo E-Mult; (3) Reflexões sobre o processo formativo E-Mult e, (4) Considerações Finais.

\section{Reflexões sobre a formação do professor dos anos iniciais do Ensino Fundamental}

O Professor mencionou em nossas discussões, que conversando com colegas, professores dos anos iniciais do Ensino Fundamental, é comum ouví-los relatar que se empenham ao máximo para ensinar o conhecimento matemático que detêm os seus alunos, mesmo assim, segundo eles, os professores de Matemática dos anos finais Ensino Fundamental reclamam que os alunos chegam no $6^{\circ}$ ano com dificuldade de interpretação, raciocínio e em conceitos básicos de Matemática. Por outro lado, segundo ele, também é comum ouvir, de seus pares, que eles se sentem despreparados ou desmotivados para o ensino de Matemática, relatando que tiveram uma formação superficial na graduação para o ensino desses conceitos e que possuem dificuldade com essa disciplina desde a Educação Básica. O que foi constatado em uma pesquisa de Lessard e Tardif (1996 apud TARDIF, 2014) ao perceberem que a falta de interesse dos professores do primário, no ensino de algumas matérias, se justifica muitas vezes por dominarem-na mal ou por considerarem-na pouco importante.

Dessa forma, em busca de suprir algumas lacunas que porventura possam existir, é importante que o professor esteja em formação contínua, buscando aprofundar em conceitos que se sentem despreparados e em outros que não foram aprendidos durante a graduação.

O Professor afirma que é preciso parar de colocar a culpa pela dificuldade dos alunos no déficit de aprendizagem de anos anteriores e ter sensibilidade para revisar aqueles conteúdos que os alunos possuem dificuldade. Reconhecendo o professor da série anterior “[...] como pessoas competentes, pares iguais que podem aprender uns com os outros (TARDIF, 2014, p. 244)”. É preciso que haja união dos professores da pré-escola a universidade, como defende Tardif (2014), quebrando o distanciamento que há entre os professores, nesse caso, o que há entre os professores dos anos iniciais com os dos anos finais do Ensino Fundamental.

O Professor também relatou enfrentar dificuldade com a disciplina de matemática durante a Educação Básica, além disso, considera que o curso de Pedagogia não foi suficiente 
para se sentir seguro em lecionar conceitos matemáticos em sala de aula, uma vez que lhe deu uma noção básica desses conceitos. Dessa forma, sentiu-se inseguro, ao ter que ministrar essa disciplina, recorrendo para isso, aos conhecimentos adquiridos em sua vivência. Um caminho utilizado pelos professores para orientar a sua prática. Assim, o professor organiza sua prática a partir da sua história de vida, de suas vivências, da sua afetividade e de seus valores. Uma vez que seus saberes estão enraizados em sua história de vida e na experiência do ofício de ser professor (TARDIF, 2014).

Segundo Tardif (2014) além dos saberes da experiência, o ofício do professor também está orientado em outros saberes, tais como "conhecer sua matéria, sua disciplina e seu programa, além de possuir certos conhecimentos relativos às ciências da educação e à pedagogia e desenvolver um saber prático baseado na sua experiência cotidiana com os alunos” (TARDIF, 2014, p. 39).

Para o Professor, não há como dizer que não obteve êxito no ensino de conceitos matemáticos, mas reconhece hoje, com mais experiência e mais qualificação, que ficou aquém do conhecimento matemático necessário para a criança obter sucesso nas séries seguintes e na sua formação como um todo. Muitas vezes se sentiu culpado ao ouvir os professores das séries finais do Ensino Fundamental reclamarem que os alunos vêm das séries iniciais com deficiências em relação a Matemática. Mas hoje, considera que os professores não são culpados, mas que a falha está nos cursos de formações de professores das séries iniciais, que proporciona ao professor conhecimentos matemáticos 'rasteiros', que não são suficientes para lecionar essa disciplina.

Diante das reflexões apresentadas, corroboramos com Tardif (2014) quando sugere que os professores deveriam ter o direito de controlar sua formação, com poder de determinar, com outros atores da educação, seus conteúdos e suas formas. A formação de professores, segundo esse autor, deveria se basear nos conhecimentos específicos da sua profissão e oriundos dela e não direcionada por conteúdos e lógicas disciplinares, que são concebidas, muitas vezes, sem nenhum tipo de relação com o ensino e com a realidade cotidiana da profissão e por professores que nunca colocaram os pés na escola.

Após apresentarmos as reflexões do Professor sobre sua formação, abordaremos a formação desenvolvida pelo E-Mult e PEM e as contribuições dessa formação para a prática e desenvolvimento profissional dos professores.

\section{O processo formativo desenvolvido pelo E-Mult e PEM}

Esse processo formativo teve como aporte teórico a Teoria dos Campos Conceituais, de Gérard Vergnaud. Dessa forma, para o leitor compreender melhor essa teoria e o processo formativo, iremos apresentar o que Vergnaud entende por Campo Conceitual e por Campo 
Conceitual Multiplicativo. Assim como, na sequência, apresentaremos, dentre os conceitos que envolvem o Campo Conceitual Multiplicativo, os que foram trabalhados na formação.

Segundo Vergnaud (2009), um Campo Conceitual é um conjunto de situações, que requer para seu tratamento uma variedade de conceitos, esquemas e representações em estreita conexão. Nessa perspectiva, Santos (2015), inspirado em Vergnaud (1983), enfatiza que uma situação, por mais simples que envolve distintos conceitos. Dessa forma, não faz sentido se referir à formação do conceito, mas sim do Campo Conceitual, que requer o domínio de vários conceitos.

Vergnaud (1996) enfatiza que o Campo Conceitual Aditivo e o Campo Conceitual Multiplicativo são alicerces para os demais conceitos matemáticos. O Campo Conceitual Multiplicativo, também chamado de Estruturas Multiplicativas, é definido por Vergnaud (1996), como um conjunto de situações, que envolvem multiplicação, divisão ou ambas, e um conjunto de conceitos e teoremas que permitem analisar as situações que dão sentido aos conceitos, como os de "proporção simples e proporção múltipla, função linear e n-linear, relação escalar direta e inversa, quociente e produção de dimensões, combinação linear e aplicação linear, fração, relação, número racional, múltiplo e divisor, etc.” (VERGNAUD, 1996, p. 168).

Sabemos que o Campo Conceitual Multiplicativo é vasto, dessa forma, assumindo o conjunto dos números racionais positivos, foi adotada para o processo formativo uma releitura feita por Magina, Santos e Merlini (2012), acerca das ideias de Vergnaud (1983, 1988, 1990; 1994), como apresentado na Figura 1.

FIGURA 1: Síntese do Campo Conceitual Multiplicativo

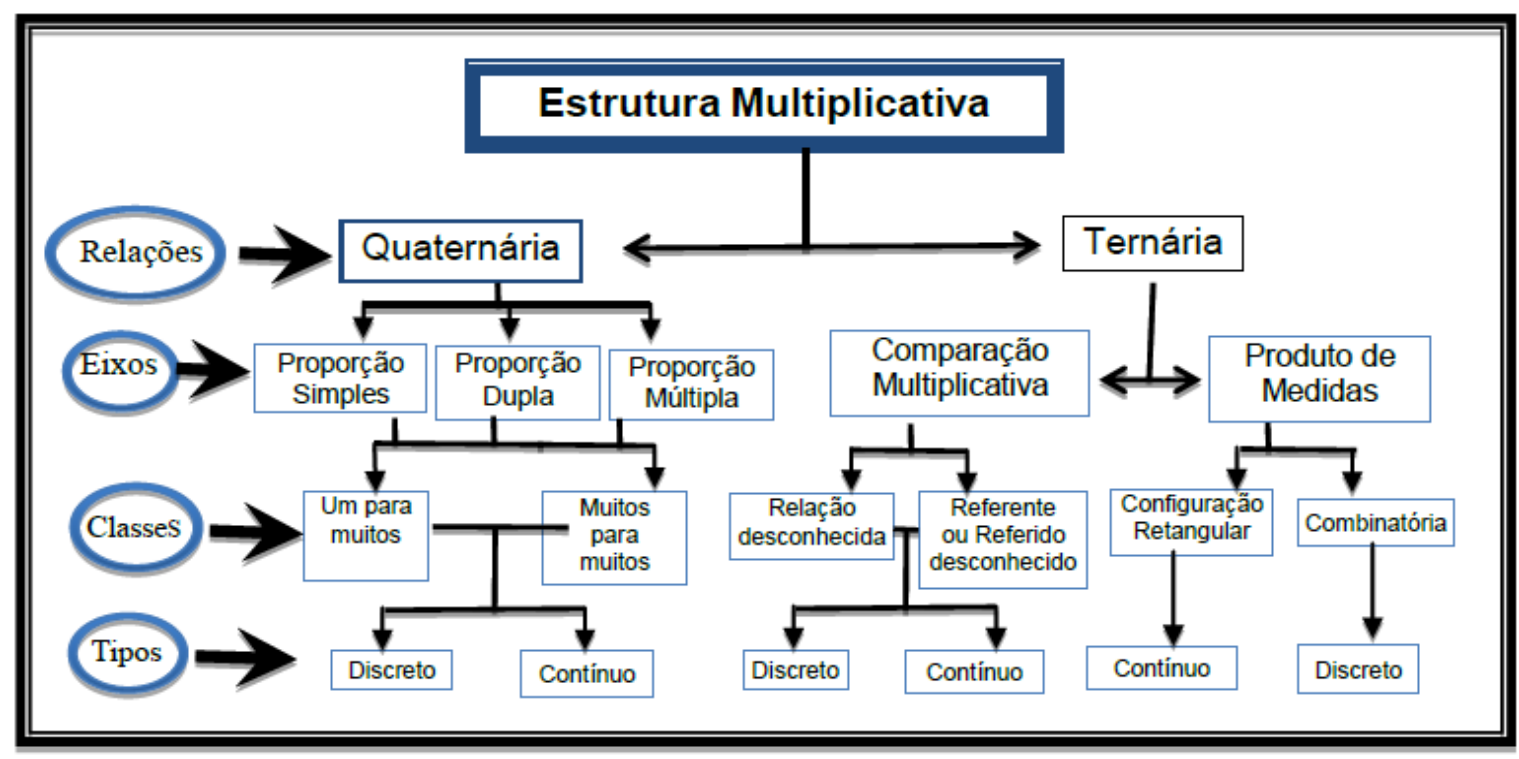

Fonte: Magina; Santos; Merlini (2012) e Santos (2015).

Dentre os conceitos apresentados na Figura 1, foi possível explorar durante o processo 
formativo a relação quaternária no eixo de proporção simples e ternária nos eixos de comparação multiplicativa e produto de medidas. Distribuídos em 10 encontros, somando uma carga horária de 66 horas.

\section{A seguir descreveremos de forma sucinta a dinâmica dos encontros formativos}

No primeiro e último encontro foi solicitado que os professores elaborassem individualmente e sem consulta, oito situações-problema envolvendo os conceitos de multiplicação e/ou divisão. A partir do segundo encontro, depois de abordar o eixo das Estruturas Multiplicativas proposto, uma das tarefas era solicitar que os professores, organizados em grupos, por ano escolar em que atuavam, elaborassem no Relatório de Atividade Planejada e socializassem em plenária, pelo menos duas situações envolvendo o eixo das Estruturas Multiplicativas trabalhado naquele encontro. Nesse instrumento, além de elaborar duas situações-problema, os professores deveriam descrever como iriam desenvolver essas situações em sala de aula, apresentando quais conceitos iriam ser trabalhados e qual seria a expectativa dos professores em relação ao desenvolvimento dos alunos.

Do terceiro encontro em diante, os professores tinham que preencher e socializar em plenária o Relatório de Atividade Desenvolvida, expondo o desenvolvimento dos alunos e como havia ocorrido a intervenção em sala de aula, a partir da atividade planejada e das situaçõesproblema elaboradas. Esse espaço de formação teve como princípio o movimento de 'açãoreflexão-planejamento-ação' apresentado na espiral da Figura 2:

FIGURA 2: Movimento do processo formativo

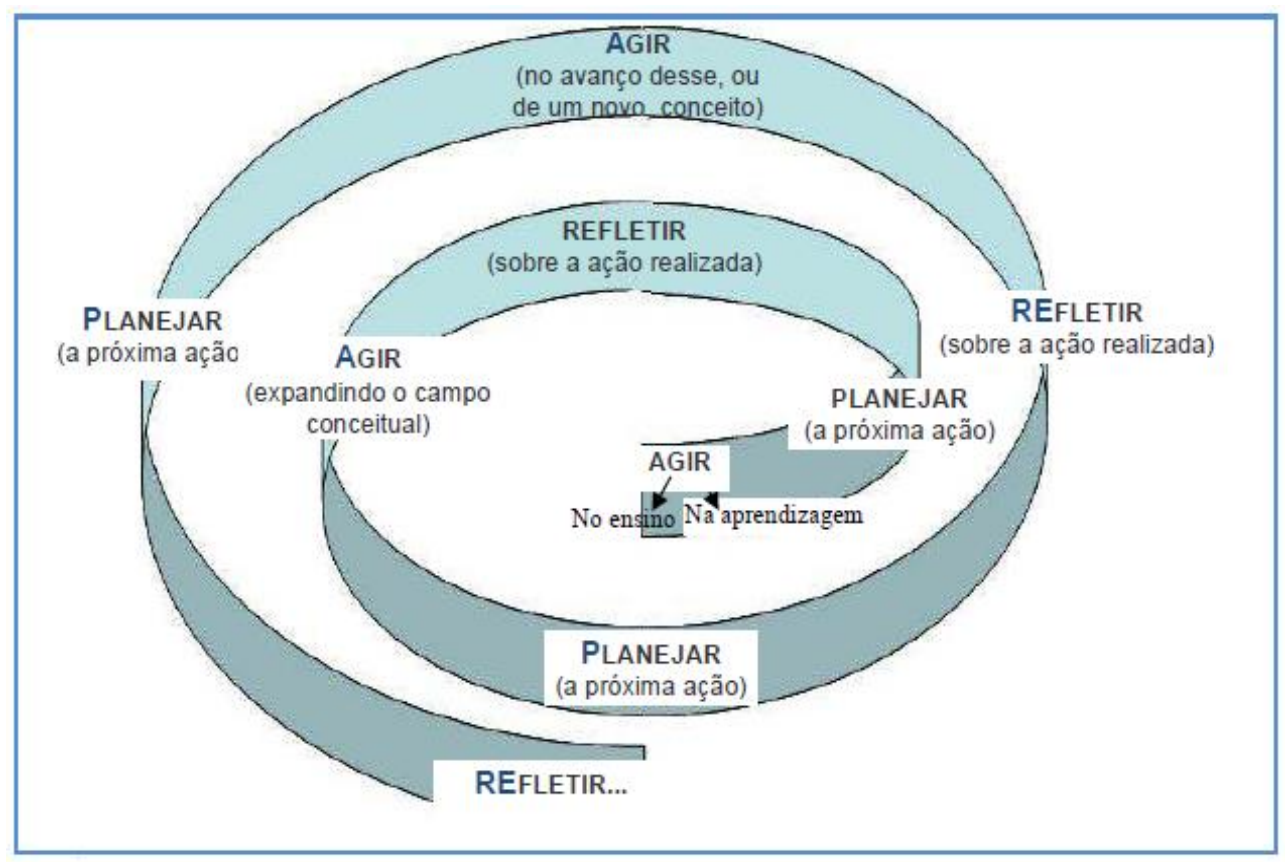

Fonte: Magina, Merlini, Santos (2012).

A espiral apresentada na Figura 2 delimitou os encontros formativos. Dessa maneira, ISSN 2526-2882 
os durante a formação desenvolvida pelo E-Mult, os professores tinham a oportunidade de (1) refletir, em grupo, sobre conceitos inerentes das Estruturas Multiplicativas, (2) elaborar situações-problema à luz desses conceitos e planejar como esses seriam explorados em sala de aula. Levando para a (3) prática de sala de aula o que o grupo achava relevante e importante ser explorado. Após a ação, retornavam para reflexão em grupo, com os resultados da intervenção feita em sala de aula, para que refletissem sobre a ação e fossem planejadas novas estratégias para atender ao público da escola, no que tange as Estruturas Multiplicativas.

Até aqui apresentamos o processo formativo desenvolvido pelo E-Mult, para entendermos melhor a dinâmica dessa formação, no tópico seguinte iremos relatar as discussões entre os autores, sobre o processo formativo, que culminou nas reflexões que traremos.

\section{Reflexões sobre o processo formativo}

O Professor relata que no início do processo formativo desenvolvido pelo E-Mult e PEM, ele ficou desconfiado, e não deu muito crédito a formação, pois já tinha passado por outras formações e participado de outras pesquisas e não tinha sido uma experiência boa. Segundo ele, em outras oportunidades, os pesquisadores chegavam, colhiam as informações, realizavam suas pesquisas e não davam nenhum retorno dos resultados, o que para ele era uma falta de consideração. Dessa forma, sentia-se como uma 'cobaia', um objeto, motivo pelo qual atualmente vinha se negando para tais propostas. Mesmo assim, resolveu dar um voto de confiança para a formação promovida pelo E-Mult e PEM.

As insatisfações apresentadas pelo Professor vêm ao encontro de Tardif (2014) ao afirmar que toda pesquisa sobre ensino tem o dever de considerar o ponto de vista do professor, assim como o seu conhecimento e o saber por ele mobilizados na ação. Baseando-se em um diálogo fecundo com os professores, "considerados não como objetos de pesquisa, mas como sujeitos competentes que detêm saberes específicos ao seu trabalho" (TARDIF, 2014, p. 230). Desta forma, há de se considerar os professores como participantes e colaboradores da pesquisa e, para tanto, tem o direito de tomar conhecimento dos seus resultados.

O Professor relata que se surpreendeu com o processo formativo, pois a formação aconteceu, como aponta Tardif (2014), sem hierarquia entre os formadores e professores, todos se respeitavam e estavam unidos, trocando conhecimento e experiência uns com os outros.

De acordo com o Professor, o momento da plenária, quando apresentavam o Relatório de Atividade Planejada, era uma oportunidade de aprender, ao ouvir a opinião do outro, discutir e dar sugestões, na busca de adequar o planejamento a partir da realidade dos alunos. Esse "aprender de forma colaborativa, dialógica, participativa, isto é, analisar, testar, avaliar e 
modificar em grupo”, segundo Imbernón (2009, p. 61) deve ser um dos pilares ou princípios para fundamentar um processo formativo.

O Professor descreve ainda, que após a aplicação do plano em sala de aula, planejado durante a formação, os professores anotavam as facilidades e dificuldades encontradas por eles e por seus alunos e na formação seguinte transcreviam para o Relatório de Atividade Desenvolvida, que era discutido com todos. Nesse momento de discussão eram sugeridas mudanças e destacados os pontos que obtiveram resultados. Assim, segundo ele, o apoio do grupo lhe trazia segurança, o que segundo Imbernón (2009, p. 28) é importante na formação docente, pois "ter o ponto de vista do outro oferece ao docente uma perspectiva diferente de como ele ou ela atuava com os estudantes", o que beneficia tanto o professor, ao receber uma devolutiva, como colega, por ter a oportunidade de discutir e de estar em contato com experiências em comum. Segundo Imbernón (2009) a prática educativa, assim como formação pessoal e profissional, precisa de processos de comunicação entre os colegas, como forma de compartilhar dúvidas, problemas, sucessos e fracassos, partilhar alegrias e tristezas, que surgem no processo de ensinar e apreender.

Esse movimento de formação não tinha sido vivenciado pelo Professor em nenhum outro curso. Para ele foi uma experiência totalmente diferente das outras que já havia participado. É possível perceber em sua fala, que nessa formação os professores eram considerados sujeitos do conhecimento e tratados como tais, tendo o mesmo direto de voz, que os formadores, assim como sugere Tardif (2014).

O Professor ressalta que dentre tantas aprendizagens com esse processo formativo, aprendeu a formular situações-problema interessantes e importantes na aprendizagem dos alunos, pois com as situações-problema os alunos passaram a ter mais interesse com as aulas de matemática, sendo instigados a resolver os problemas propostos. Com as mudanças que o processo formativo refletiu na sua prática, o Professor passou a ver aquilo que era uma 'matéria de temor', com prazer, algo desejável por seus alunos.

Para exemplificar o desenvolvimento dos alunos, o Professor contou uma situação que aconteceu em sala de Aula. Ele desenhou uma maçã na lousa para explicar um conteúdo de ciências, e disse: vejam essa maçã meninos! Foi quando um deles lhe surpreendeu, dizendo: tio isto não é uma maçã, é uma representação de uma maçã. Para ter certeza do que o aluno estava lhe falando, ele o indagou: como assim? Então o aluno completou: a gente não pode pegar e nem comer essa maçã aí, e a maçã de verdade a gente pode. Ou seja, o aluno estava sendo capaz de levar as discussões que vinham ocorrendo nas aulas de Matemática para aulas de outras disciplinas. Raciocínio e intepretação que segundo o Professor, é advindo das mudanças que ocorreram em sua prática após o processo formativo.

O Professor relata também que agora se sente motivado durante as aulas de 
matemática e mais preparado para ensinar conceitos matemáticos aprendidos no processo formativo, que antes não tinha domínio. Para ele, aprender algo novo não foi fácil, assim reconhecer que tinha que fazer algo diferente em sala de aula. Apesar de não ser fácil, a formação possibilitou reconstruir sua prática e adquirir conhecimento teórico, o que foi de suma importância.

Nessa perspectiva, Imbernón (2009) sugere que em qualquer transformação educativa, o professor deve constatar não só o aperfeiçoamento da formação de seus alunos, mas deve também perceber benefícios em sua formação e em seu desenvolvimento profissional. Foi nesse sentido, que o Professor se surpreendeu com a formação desenvolvida pelo E-Mult e PEM, pois viu que as mudanças na prática oferecida por esse processo formativo repercutiu na aprendizagem de seus alunos, ao mudarem suas crenças e atitudes, trazendo benefícios para os alunos e para a sua forma de exercer a docência, assim, o Professor deixou “[...] de ver a formação não tanto como uma 'agressão' externa, mas como um benefício individual e coletivo" (IMBERNÓN, 2009, p.27).

\section{Considerações Finais}

A partir das reflexões apresentadas, percebemos que o Professor se surpreendeu com o processo formativo desenvolvido pelo E-Mult, uma vez que esse aconteceu sem hierarquia entre os formadores e professores, o que segundo ele não foi comum em outras formações que participou. Nesse processo formativo os professores tiveram voz podendo opinar e discutir, o que foi uma oportunidade rica de aprendizagem, de acordo com o Professor.

Fica evidente ainda, nas reflexões do Professor, que as formações sejam diferenciadas. Isso significa que precisamos ouvir o que o professor tem a dizer, qual a sua real necessidade, proporcionando um ambiente que se discuta suas experiências e inquietações. Somado a isso, que o professor possa experimentar em sala de aula o que é discutido na formação e, além disso, possa dividir suas dificuldades com seus pares e com os formadores.

Para melhorar a dinâmica do processo formativo, buscamos junto ao professor pontos da formação que ele acredita que devem ser aprimorados. Esse indicou a necessidade de se aprofundar mais em um conceito, pois acredita que a formação deu possibilidade dos professores terem uma ideia de vários conceitos, mais precisariam de mais tempo para adquirir mais domínio. Sugeriu ainda, encontros formativos com maior regularidade, podendo ser quinzenais, segundo ele, pois os encontros ocorriam com períodos longos, cerca de um mês, o que fazia com que os professores se envolvessem em outras atividades e se distanciassem das desenvolvidas no processo formativo.

Diante do que foi apontado pelo professor, temos a clareza que 66 horas dedicados ao processo formativo desenvolvido pelo E-Mult não tem a intenção de preencher todas as lacunas 
apresentadas pelos professores, contudo, ao menos para esse Professor possibilitou uma ideia da Estrutura Multiplicativa e entusiasmo com relação à Matemática. Porém, como esse é um campo conceitual vasto, sabemos que essa aprendizagem demanda tempo, por isso, esse é um processo que necessita de continuidade.

\section{Referências}

IMBERnÓN, F. Formação Permanente do Professor: Novas tendências. São Paulo: Cortez, 2009.

LIMA, D. C. A formação continuada de professores que ensinam matemática nos anos iniciais e as estruturas multiplicativas. 2016. $161 \mathrm{f}$. Dissertação (Mestrado em Educação Matemática) - Universidade Estadual de Santa Cruz, Programa de PósGraduação em Educação Matemática, Ilhéus. 2016.

MAGINA, S.; SANTOS, A.; MERLINI, V. A estrutura Multiplicativa sob a ótica da Teoria dos Campos Conceituais: uma visão do ponto de vista da aprendizagem. In: $3^{\mathrm{o}}$ SIMPÓSIO INTERNACIONAL DE PESQUISA EM EDUCAÇÃO MATEMÁTICA. Fortaleza: Universidade Federal do Ceará, v. 1. p. 1-12, 2012.

SANTOS, A. Formação de Professores e as estruturas multiplicativas: reflexões teóricas e práticas. 1 ed. Curitiba: Appris, 2015.

TARDIF, M. Saberes docentes e formação profissional. 17. ed. Petrópolis, RJ: Vozes, 2014.

VERGNAUD, G. A Teoria dos Campos Conceituais. In: BRUN, J. Didáctica das matemáticas. Tradução por Maria José Figueiredo. Lisboa: Instituto Piaget, 1996. P. 155-191.

. O que é aprender? In: BITTAR, M; MUNIZ, C. A. (orgs.). A Aprendizagem Matemática na Perspectiva da Teoria dos Campos conceituais. Curitiba: Editora CRV, 2009. p. 13-36.

\section{Biografia Resumida}

Deusdete Luiz da Silva Filho: funcionário público efetivo, professor com dedicação exclusiva com 40 horas, graduado em pedagogia pela uesb universidade estadual do Sudoeste da Bahia em (2010). pos graduando em psicopedagogia com atendimento clínico, hospitalar e institucional pelo iseo, bacharelando em direito, pos graduando em fase final em coordenação e planejamento escolar pela instituição interclasse, e com 
formação técnica em técnico em contabilidade em 1985. escritor conjuntamente com adriana costa santos da silva de literatura infantil, com obras concluídas prontas para serem publicadas

Link Lattes: http://lattes.cnpq.br/3445163077282837

e-mail: deusdetelsf@bol.com.br

Pedro Henrique Milagre: Mestrando em Educação Matemática pelo Programa de Pós-Graduação em Educação Matemática (PPGEM) da Universidade Estadual de Santa Cruz (UESC). Graduado em Licenciatura Plena em Matemática pelo Instituto Federal de Educação, Ciência e Tecnologia do Espírito Santo (IFES).

Link Lattes: http://lattes.cnpq.br/7280214586552638

e-mail: phmilagre@gmail.com 